\title{
Análise morfométrica das cavernas quartzíticas da região de Itambé do Mato Dentro, Serra do Espinhaço Meridional - MG
}

\author{
Morphometric analyzes of quartzite caves in Itambé do Mato Dentro region, Serra do \\ Espinhaço meridional - MG
}

\author{
Fabiana Pena Fabri \\ Mestre em Geografia pela UFMG \\ Belo Horizonte, Brasil \\ fpfabri@yahoo.com.br
}

Artigo recebido para revisão em 16/02/2013 e aceito para publicação em 09/05/2013

\begin{abstract}
RESUMO
Atualmente ainda existe grande controvérsia em relação ao termo a ser empregado a feições assemelhadas a formas cársticas geradas por dissolução, porém ocorrentes em litologias pouco solúveis, notadamente os quartzitos e arenitos. Tal fato é decorrente dos poucos estudos de detalhe gerados nessas rochas, não havendo no meio científico, um consenso com relação aos mecanismos condicionantes no desenvolvimento dessas formas. Além disso, esses estudos são quase sempre abordados de forma descritiva e qualitativa em relação aos processos atuantes, carecendo de estudos de caráter quantitativo. O presente trabalho apresenta os principais resultados das análises morfométricas das cavernas quartzíticas localizadas no município Itambé do Mato Dentro - MG. Esses estudos tiveram como propósito investigar e quantificar informações sobre a morfometria das cavidades da área de estudo, a partir da comparação com dados de outras cavernas desenvolvidas em rochas siliciclásticas, além das que foram alvo dessa pesquisa. Os resultados mostraram que as cavernas em rochas siliciclásticas tendem a apresentar valores morfométricos baixos, indicando que o processo de carstificação nessas litologias é menos expressivo que nos terrenos carbonáticos. A forte correlação registrada entre os parâmetros projeção horizontal, área e distância entre extremos demonstra que existe um forte controle estrutural sobre as cavernas em rochas siliciclásticas.
\end{abstract}

Palavras-chave: Cavernas, Rochas Siliciclásticas, Análise Morfométrica, Serra do Espinhaço.

\begin{abstract}
Currently there is still much controversy regarding the term to be used to karst features which are similar to the forms generated by dissolution, but occurring in poorly soluble lithologies, mainly quartzites and sandstones. This fact is due to the few detailed studies generated in these rocks which result in an absence of consensus among scientists regarding the mechanisms that condition the development of these forms. Furthermore, these studies are almost always dealt in a qualitatively and descriptively way in relation to active processes lacking a quantitative studies. This paper presents the main results of morphometric analyzes of quartzite caves located in Itambé Mato Dentro county - MG. These studies were aimed to investigate and quantify information about the morphology of the cavities of the study area, from the comparison with data from other caves developed in siliciclastic rocks, besides the ones that were target of this research. The results showed that the caves in siliciclastic rocks tend to have low morphometric values, indicating that the process of karstification of these lithologies is less significant than in carbonate terrains. The strong correlation between the parameters on horizontal projection area and distance between extremes shows that there is a strong structural control on the caves in siliciclastic rocks.
\end{abstract}

Keywords: Caves, Siliciclastic Rocks, Morphometric Analyzes, Serra do Espinhaço. 


\section{INTRODUÇÃO}

Atualmente existem diversos relatos no mundo sobre grandes sistemas de cavernas, dolinas entre outras feições cársticas, desenvolvidas em rochas quartzíticas (WHITE et al., 1966; SZCZERBAN; URBANI, 1986; MARTINI, 1979; JENNINGS, 1983; WRAY, 1997). Embora não sejam feições exclusivamente encontradas na América do Sul (DOERR, 1999), esta região abriga um grande número de cavernas nessa litologia, com dimensões bastante expressivas (AULER, 2004). Cavernas em rochas siliciclásticas abundam sobre o território brasileiro, ocorrendo sob diversos domínios climáticas (SUGUIO, 1999; SILVA, 2004).

Na região denominada por Suguio (1999), como Província Espeleológica Serra do Espinhaço, estão localizadas cavernas em rochas quartzíticas e areníticas, que já foram objeto de importantes estudos (BRICHTA et al., 1980; WIEGAND et al., 2004; CRUZ et al., 1999). No município de Itambé do Mato Dentro - MG, localizado na borda leste da Serra do Espinhaço Meridional, um grupo de cavernas em rochas quartzíticas foram estudadas por Fabri (2011).

A pesquisa teve como objetivo principal, investigar os processos que levaram a gênese das feições interpretadas como cárstica. Visando melhor compreender o desenvolvimento das cavernas, foram aplicados também métodos morfométricos para uma sistematização das grutas em rochas siliciclásticas.
Os estudos relacionados ao meio cárstico siliciclástico ainda encontram-se em estágio incipiente, não havendo no meio científico um consenso com relação aos mecanismos condicionantes dessas formas. Devido a este fato há, ainda hoje, controvérsias no meio acadêmico sobre a questão terminológica a ser empregada para feições como cavernas, lapiás e dolinas ocorrentes em arenitos e quartzitos (URBANI, 1986; WRAY, 1997; JENNINGS, 1983; YOUNGER; STUNELL，1995). Além disso, esses estudos quase sempre são abordados de forma descritiva e qualitativa em relação aos processos atuantes carecendo, portanto, de estudos de caráter quantitativo.

O presente trabalho apresenta os principais resultados das análises morfométricas de dez cavernas quartzíticas, localizadas no município de Itambé do Mato Dentro. Esses estudos tiveram como propósito investigar e quantificar informações sobre a morfometria das cavidades da área de estudo, a partir da comparação com dados de outras cavernas desenvolvidas em rochas siliciclásticas, além das que foram alvo dessa pesquisa.

\section{MATERIAIS E MÉTODOS}

$\mathrm{Na}$ análise morfométrica foram avaliadas 10 cavernas quartzíticas, localizadas no município de Itambé do Mato Dentro. Inclui-se nessa análise uma amostragem de 67 cavernas em rochas siliciclásticas, localizadas em todo território brasileiro. Essas cavernas foram objeto de análise morfométrica por Silva (2004), que 
incluem também 12 cavidades localizadas na Serra do Ibitipoca, em Minas Gerais.

Neste grupo, que será mencionado no trabalho como "grutas totais", não foram levados em conta os dados referentes às grutas Alaouf, Bocaína, Centenário e Fumaça, localizadas na Serra do Caraça (MG), uma vez que destoam muito em relação às demais grutas, principalmente quanto aos parâmetros projeção horizontal e desnível. Estas pertencem ao grupo das grutas verticalizadas, desenvolvidas em descontinuidades tectônicas. Já as demais, referem-se ao que Auler (2004) define como grutas de frente de cuesta, correspondente a grande maioria das cavernas em rochas siliciclásticas encontradas até o momento.

Para a análise morfométrica foram utilizados 8 parâmetros quantitativos desenvolvidos e aplicados por Silva (2004). Esses parâmetros são: projeção horizontal, distância entre extremos, área, densidade de área, desnível, número de entradas, conectividade e sinuosidade.

Os dados desses parâmetros foram obtidos a partir da topografia das cavernas estudadas e calculados através do software AutoCAD 2012. Em seguida, esses dados foram comparados com os dados morfométricos das 67 cavernas em rochas siliciclásticas de outras regiões.

Posteriormente, foram realizadas as correlações entre alguns parâmetros, através do cruzamento das variáveis, utilizando como instrumento de correlação linear, o Coeficiente de Pearson, de acordo com a interpretação dos valores de $r$ (Tabela 1).
Tabela 1 - Interpretação do Coeficiente de Pearson.

\begin{tabular}{lr}
\multicolumn{1}{c}{$\begin{array}{c}\text { COEFICIENTE DE } \\
\text { CORRELAÇÃO }\end{array}$} & \multicolumn{1}{c}{ CORRELAÇÃO } \\
$\mathbf{r}=\mathbf{1}$ & Perfeita positiva \\
$\mathbf{0 , 8} \leq \mathbf{r}<\mathbf{1}$ & Forte positiva \\
$\mathbf{0 , 5} \leq \mathbf{r}<\mathbf{0 , 8}$ & Moderada positiva \\
$\mathbf{0 , 1} \leq \mathbf{r}<\mathbf{0 , 5}$ & Fraca positiva \\
$\mathbf{0}<\mathbf{r}<\mathbf{0 , 1}$ & Ínfima positiva \\
$\mathbf{0}$ & Nula \\
$\mathbf{- 0 , 1}<\mathbf{r}<\mathbf{0}$ & Ínfima negativa \\
$\mathbf{- 0 , 5}<\mathbf{r} \leq \mathbf{- 0 , 1}$ & Fraca negativa \\
$\mathbf{- 0 , 8}<\mathbf{r}-\mathbf{0 , 5}$ & Moderada \\
& negativa \\
$\mathbf{- 1}<\mathbf{r} \leq \mathbf{- 0 , 8}$ & Forte negativa \\
$\mathbf{r}=\mathbf{- 1}$ & Perfeita negativa \\
\hline
\end{tabular}

O quadro da Figura 1, ao final do artigo, esclarece cada parâmetro utilizado para quantificar formas em cavernas e sua finalidade.

\section{ANÁLISE MORFOMÉTRICA}

A Tabela 2 apresenta os dados morfométricos das grutas de Itambé do Mato Dentro. A seguir serão apresentados as análises de cada parâmetro.

\section{Projeção Horizontal}

Conforme observado por Silva (2004), as grutas desenvolvidas em rochas siliciclásticas tendem a apresentar baixo grau de desenvolvimento em relação às cavernas carbonáticas. 
Tabela 1 - Dados morfométricos das cavernas de Itambé do Mato Dentro.

\begin{tabular}{|c|c|c|c|c|c|c|c|c|c|c|}
\hline ID & $\begin{array}{c}\text { Cavidades } \\
\text { naturais } \\
\text { subterrâneas }\end{array}$ & $\begin{array}{l}\text { PH } \\
(\mathbf{m})\end{array}$ & $\begin{array}{l}\text { Desnível } \\
\text { (m) }\end{array}$ & $\begin{array}{l}\text { Área } \\
\left(\mathrm{m}^{2}\right)\end{array}$ & Densidade & $\begin{array}{l}\text { Dist. } \\
\text { extremos } \\
\text { (m) }\end{array}$ & Sinuosidade & Conect. & $\begin{array}{c}\mathrm{N} \text { de } \\
\text { entradas }\end{array}$ & Hierarq \\
\hline 1 & $\begin{array}{c}\text { Abrigo das } \\
\text { Pinturas }\end{array}$ & 65 & 8 & 518 & 0,156 & 65 & - & 0 & 1 & - \\
\hline 2 & $\begin{array}{c}\text { Gruta } \\
\text { Baixada das } \\
\text { Crioulas I }\end{array}$ & 1074 & 75 & 6660 & 0,05 & 517,13 & 1,12 & 19 & 10 & 2 \\
\hline 3 & $\begin{array}{c}\text { Gruta } \\
\text { Baixada das } \\
\text { Crioulas II }\end{array}$ & 205 & 13,5 & 1777 & 0,19 & 163,77 & 1,04 & 2 & 3 & 2 \\
\hline 4 & $\begin{array}{l}\text { Gruta dos } \\
\text { Milagres I }\end{array}$ & 225 & 14 & 1100 & 0,0586 & 125,72 & - & 12 & 3 & \\
\hline 5 & $\begin{array}{c}\text { Gruta dos } \\
\text { Milagres II }\end{array}$ & 149 & 17 & 806 & 0,113 & 143,62 & 1,01 & 0 & 2 & 1 \\
\hline 6 & $\begin{array}{l}\text { Toca da } \\
\text { Esteira }\end{array}$ & 96 & 28 & 335 & 0,142 & 68,55 & 1,01 & 5 & 4 & 1 \\
\hline 7 & $\begin{array}{l}\text { Toca do } \\
\text { Funil I }\end{array}$ & 21 & 4 & 141 & 1,433 & 21 & 1,01 & 0 & 1 & - \\
\hline 8 & $\begin{array}{l}\text { Toca do } \\
\text { Funil II }\end{array}$ & 106 & 29 & 534 & 0,0945 & 105,22 & 1,01 & 0 & 1 & 2 \\
\hline 9 & $\begin{array}{l}\text { Toca do } \\
\text { Gentio }\end{array}$ & 14 & 2 & 53 & 0,571 & 13,68 & 1,03 & 0 & 1 & 1 \\
\hline 10 & Toquinha & 6 & 1,5 & 9,3 & 0,153 & 6 & 1 & 0 & 1 & 1 \\
\hline
\end{tabular}

*Os quadros em branco referem-se às cavernas sem drenagem ou com cursos d'água intermitente.

De acordo com a Figura 2, grande parte das cavidades siliciclásticas, isto é, $38,9 \%$ das grutas totais não ultrapassam os $100 \mathrm{~m}$. Outro grupo expressivo de cavernas representado por $36,4 \%$ das grutas totais, encontra-se entre as faixas de 100-200 m e 201-300 m. Sendo assim, $73,3 \%$ das cavernas totais não ultrapassam os $300 \mathrm{~m}$ de desenvolvimento, podendo ser consideradas pequenas. No entanto, embora prevaleçam as cavidades pequenas, $12,9 \%$ das grutas totais superam os $500 \mathrm{~m} \mathrm{e}, 5,2 \%$ apresentam desenvolvimento superior a $1 \mathrm{~km}$. caverna grande.
Estes resultados são bastante representativos em se tratando de cavernas em rochas siliciclásticas.

Quanto às grutas de Itambé do Mato Dentro os resultados são bastante semelhantes, ou seja, há um predomínio de cavernas inferiores a $100 \mathrm{~m}$, relativo a $50 \%$, e $40 \%$ encontra-se entre as faixas de $100-200 \mathrm{~m}$ e 201 300m. Apenas uma amostra apresenta desenvolvimento superior a $1 \mathrm{~km}$, a Gruta Baixada das Crioulas I, com 1074 m de projeção horizontal, podendo ser considerada uma 


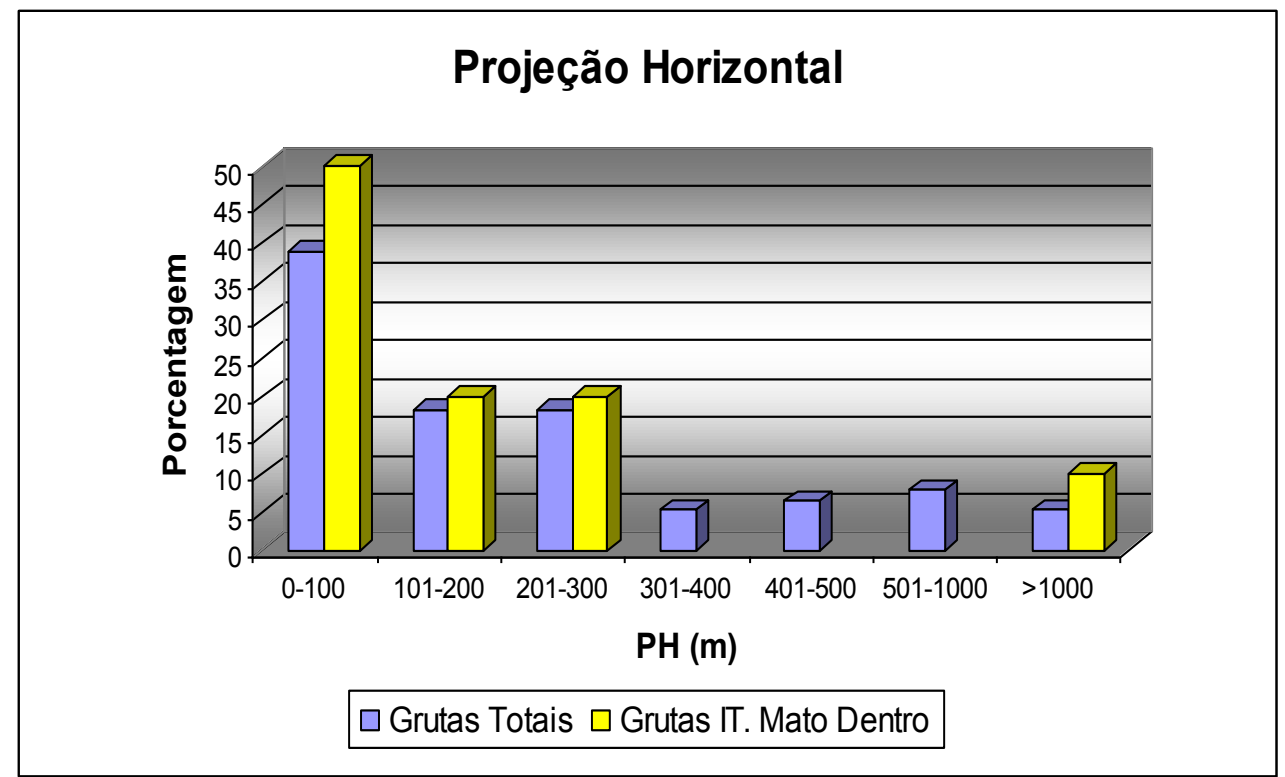

Figura 2 - Gráfico de distribuição sobre o desenvolvimento das cavernas siliciclásticas (Fonte: FABRI, 2011).

\section{Distância entre Extremos}

Considerando que as grutas em rochas siliciclásticas são predominantemente pequenas, era de se esperar que tal tendência seria observada também para o parâmetro de distância entre extremos. Os dados representados pela Figura 3, demonstram que a maior parte das cavernas em rochas siliciclásticas não ultrapassam os $100 \mathrm{~m}$, podendo ser confirmada respectivamente pelo valores $53,2 \%$ e $50 \%$, para as Grutas totais e para as Grutas de Itambé do Mato Dentro.

É interessante observar que essa correlação positiva entre projeção horizontal e distância entre extremos, não se aplica às cavidades maiores. De forma geral, nas grandes cavidades a distância entre extremos é menor em relação ao seu desenvolvimento, possivelmente pela existência de condutos laterais conectados ao principal

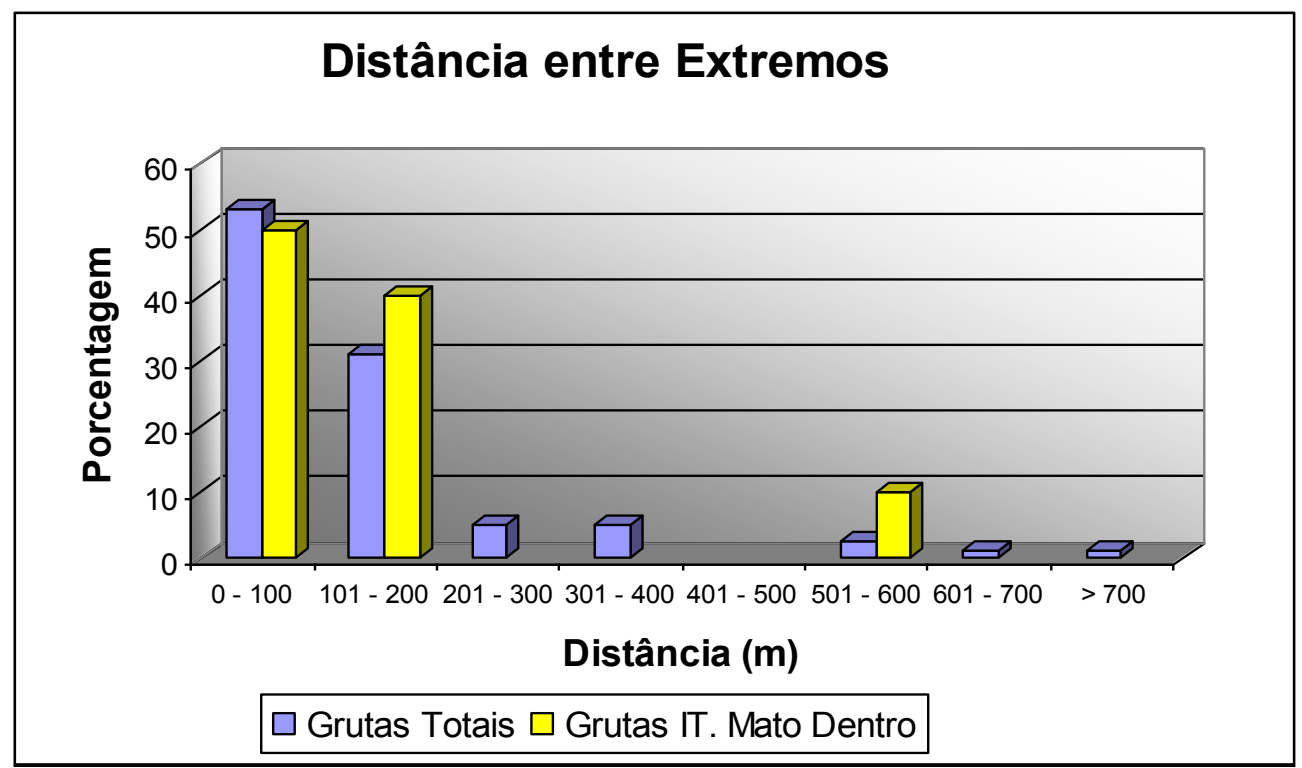

Figura 3 - Gráfico de distribuição de distância entre extremos em grutas siliciclásticas (Fonte: FABRI, 2011). 
Área

Após a apuração dos dados, foi possível observar que o parâmetro área também se correlaciona com a projeção horizontal. Os resultados, representados na Figura 4, demonstram que $59,7 \%$ das grutas totais ocupam área inferior a $100 \mathrm{~m}^{2}$, assim como a maioria das cavernas da área de estudo, representada por $70 \%$. O percentual reduz fortemente em direção as classes de áreas cujos valores são mais elevados.

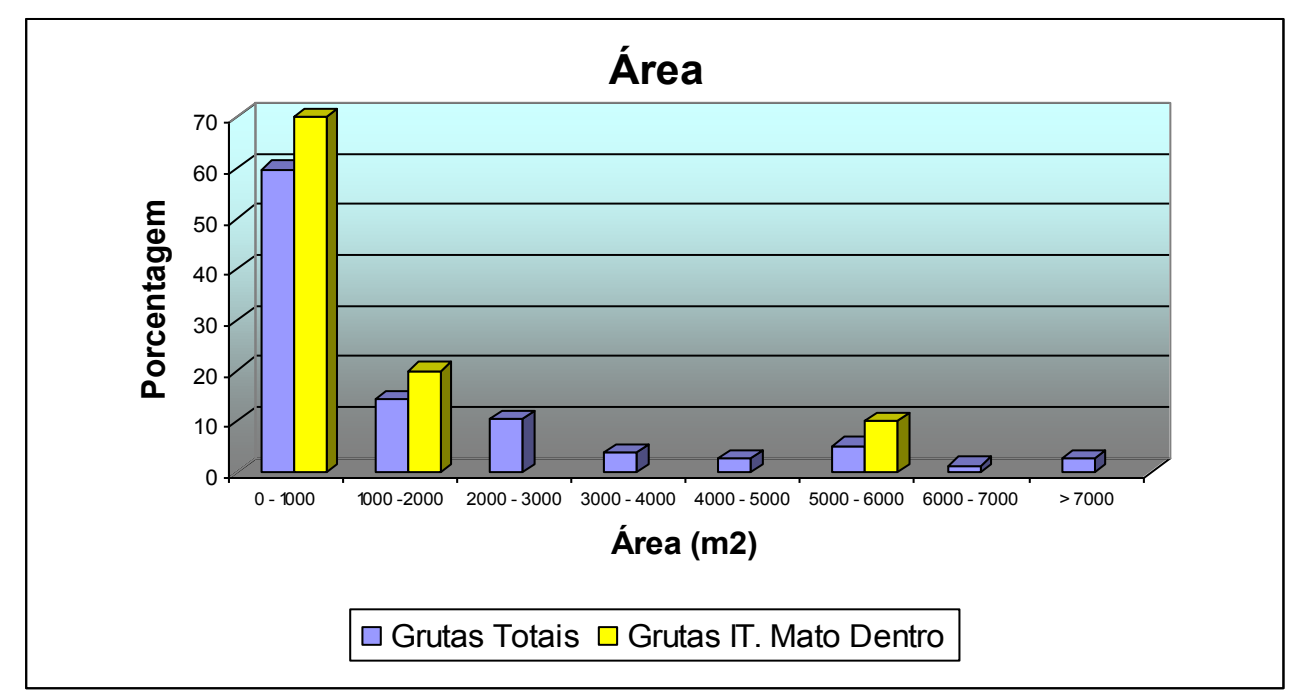

Figura 4 - Gráfico de distribuição da área em cavernas siliciclásticas (Fonte: FABRI, 2011).

\section{Densidade de área}

De acordo com os dados analisados, conclui-se que para as grutas totais predominam as densidades de áreas situadas entre $0,1-0,2$, que correspondem a 37,7\%. Registra-se também uma boa representatividade para faixas $0-0,1$ e $0,2-0,3$, que juntas somam o percentual de $36,4 \%$. A partir da terceira classe, no entanto, o percentual tende a decrescer (Figura 5).

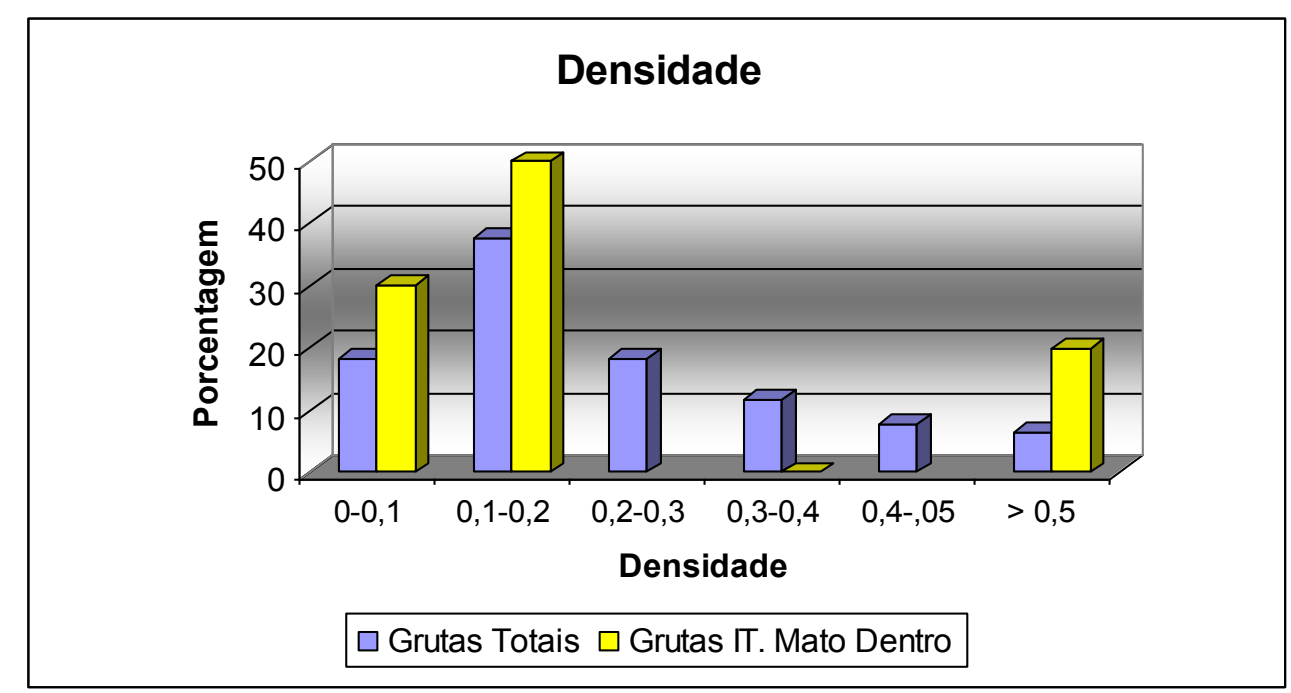

Figura 5 - Gráfico de distribuição de densidade em grutas siliciclásticas. (Fonte: FABRI, 2011). 
Sobre as cavernas de Itambé do Mato Dentro, conforme apresentado na Figura 6, os resultados são muito similares aos das grutas totais. Há o predomínio da segunda classe, com $50 \%$, sendo que as densidades entre $0-0,1$, também são significativas, com $30 \%$. As grutas menores, entretanto, tendem a ocupar maior densidade de área.

\section{Conectividade}

Os números mostram que $51,9 \%$ das grutas totais exibem um número pequeno de conexões, entre 1 a 5\%. Embora haja uma forte tendência para baixa conectividade, a porcentagem de cavernas que apresentam nenhuma conectividade é representada por apenas $15,6 \%$ do total. Diferentemente do que foi constatado para área de estudo, onde $60 \%$ das cavernas apresentam ausência de conexões (Figura 6).

A partir da análise dos resultados deste parâmetro, observa-se que as cavernas em rochas siliciclásticas tendem a apresentar baixa conectividade. Isso se deve ao fato de que as cavernas nessas litologias apresentam baixo desenvolvimento. Esta relação, entretanto, será melhor explicada mais adiante.

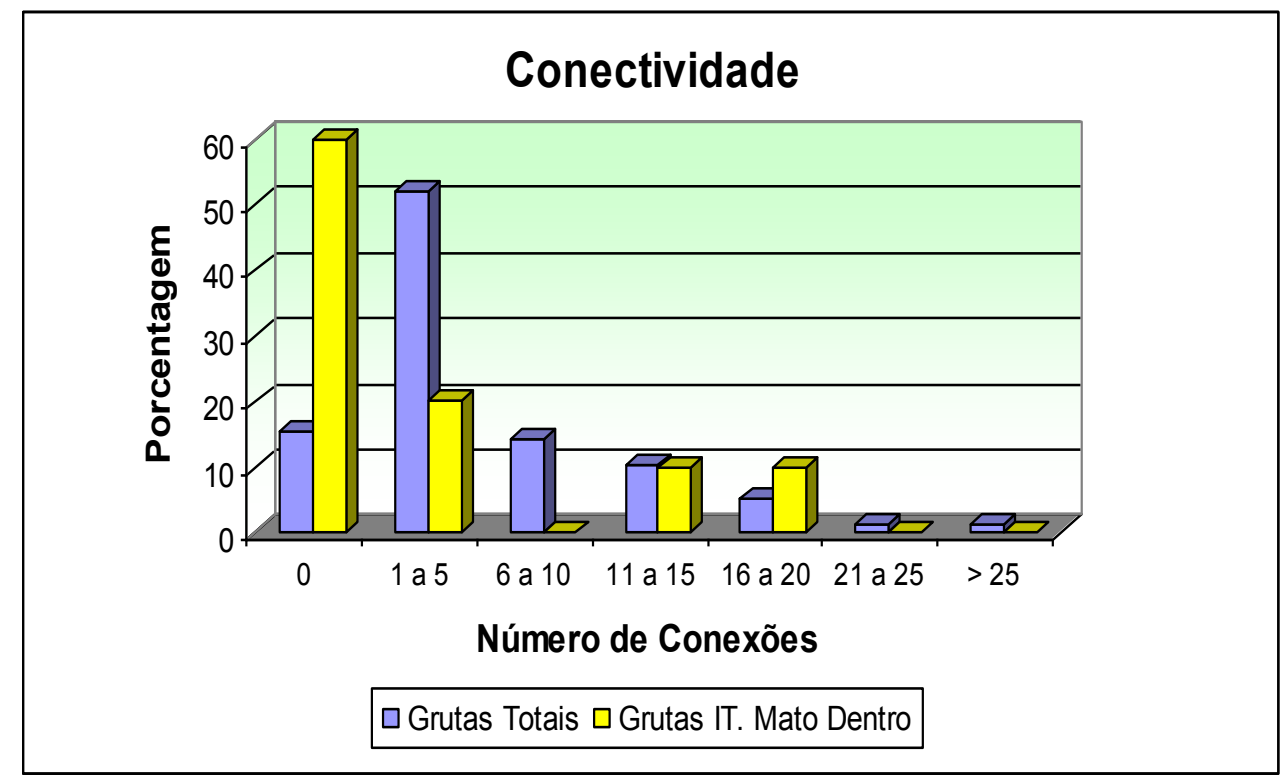

Figura 6 - Gráfico de distribuição sobre conectividade em cavernas siliciclásticas (Fonte: FABRI, 2011).

\section{Número de Entradas}

De acordo com a análise dos dados deste parâmetro, houve um predomínio de cavernas com apenas uma entrada, representadas por $38,9 \%$ das grutas totais. Outro grupo significativo foi aquele com cavernas de duas entradas, representado por $28,6 \%$ das grutas totais (Figura 7).

Em relação às cavernas de Itambé do Mato Dentro, a distribuição entre as classes varia um pouco, mas a maior freqüência, ou $50 \%$ das cavidades também é representada pelo grupo de cavernas de uma entrada, em função 
do seu pequeno desenvolvimento (Figura 7). É importante destacar que a maior caverna da área, a Gruta Baixada das Crioulas I, possui 10 entradas.
Dessa forma concluí-se, que, de forma geral, as grutas em rochas siliciclásticas tendem a apresentar um número reduzido de entradas, em função do seu baixo desenvolvimento.

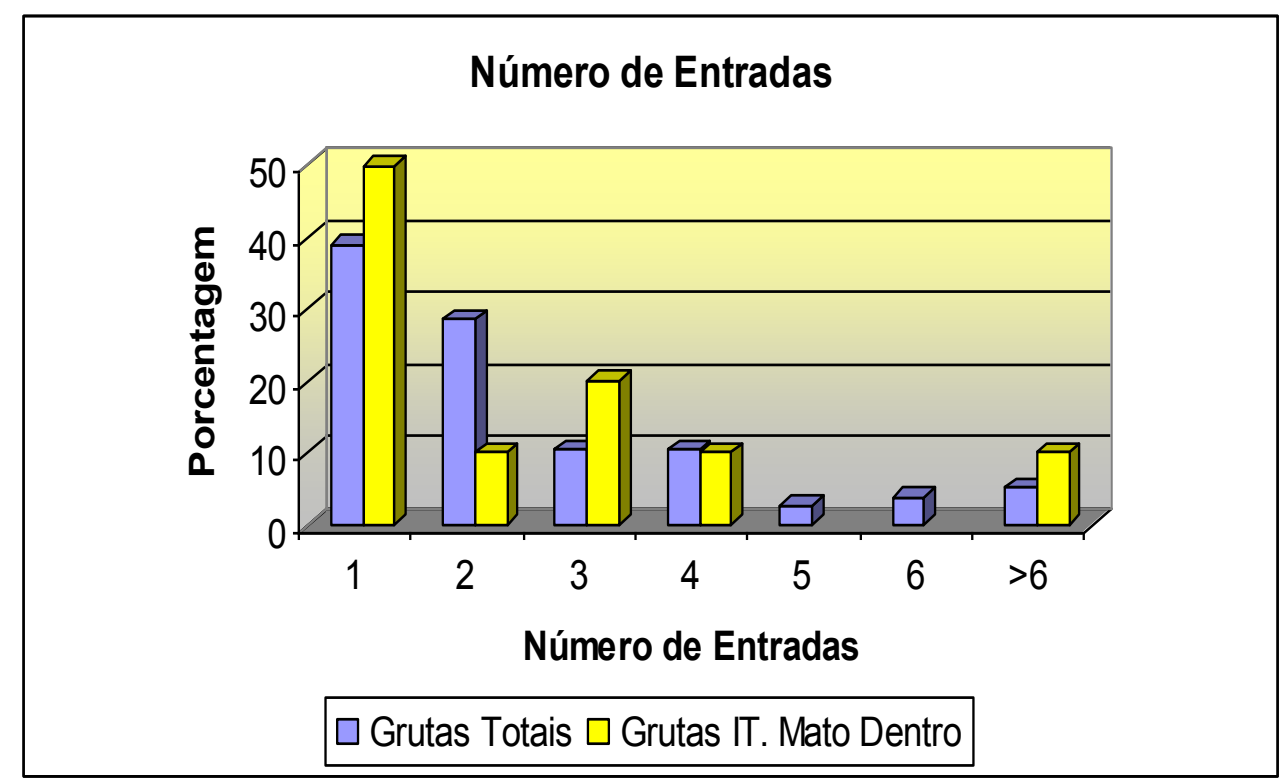

Figura 7 - Gráfico de distribuição do número de entradas em grutas siliciclásticas (Fonte: FABRI, 2011).

\section{Desnível}

De forma geral, o desnível das grutas em rochas siliciclásticas pode ser considerado baixo.

Com base na análise dos dados desse parâmetro, tanto as grutas totais quanto as grutas da área de estudo, se concentram na faixa de desnível entre 0-10 metros representada, respectivamente, pelos valores $43,1 \%$ e $40 \%$. Se considerarmos em até 20 metros de desnível, a porcentagem sobe, respectivamente, para $83,1 \%$ e $70 \%$ (Figura 8 ).

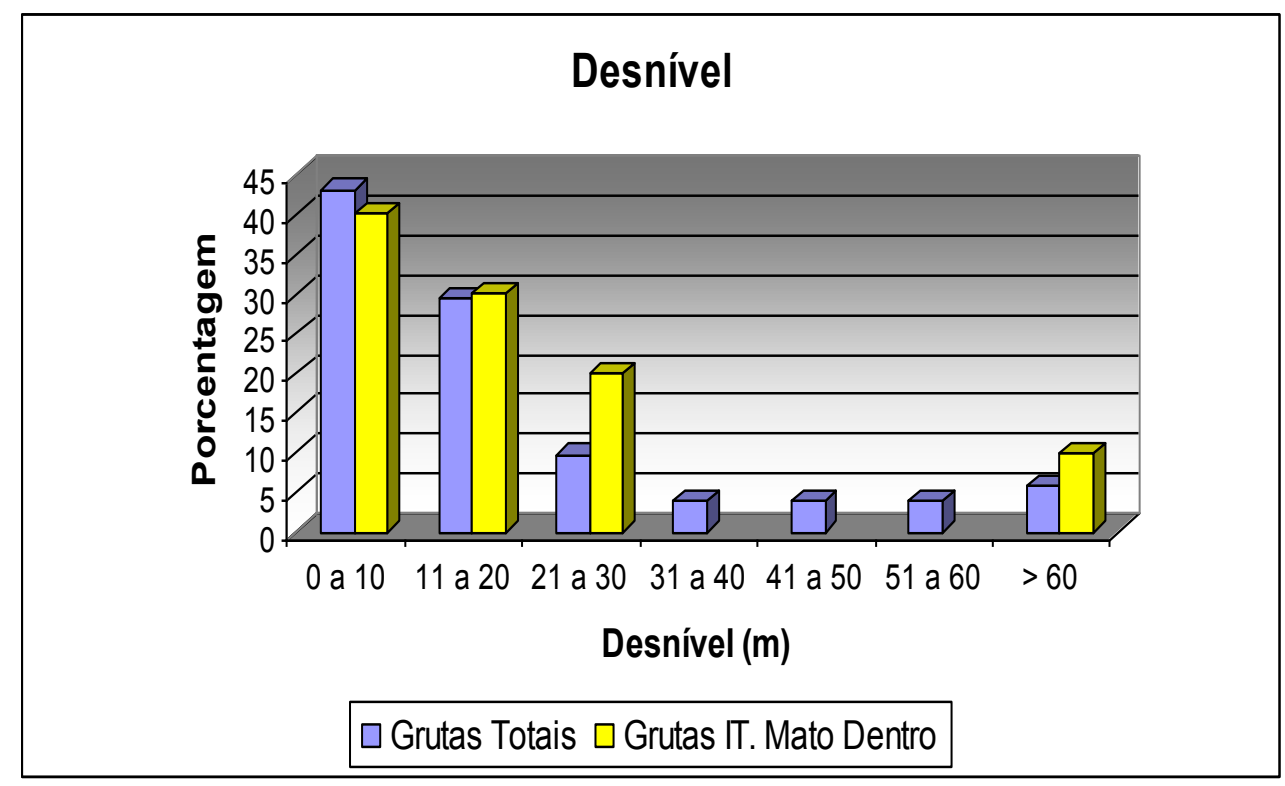

Figura 8 - Gráfico de distribuição do desnível em grutas siliciclásticas (Fonte: FABRI, 2011). 
As grutas de Itambé do Mato Dentro apresentaram inclinações predominantemente pouco acentuadas ao longo de suas galerias, pois, normalmente, são condicionadas pela direção e / ou mergulho dos planos estratigráficos que tendem a apresentar baixo grau de inclinação. Isto reflete em um baixo grau de inclinação das grutas da área de estudo, com exceção da Gruta Baixada das Crioulas I que apresenta $75 \mathrm{~m}$ desnível. O alto desnível desta caverna estaria associado a mudanças no controle estrutural da mesma, entre direção (strike) e mergulho (dip) das camadas da rocha, dando origem a trechos de poços e corredeiras.

\section{Hierarquização de Rede}

A partir das análises verificou-se que as grutas em rochas siliciclásticas também não tendem a desenvolver grandes redes hierarquizadas, em função, provavelmente do seu baixo desenvolvimento.

Os dados revelam que $54,8 \%$ das grutas totais apresentam apenas canais de primeira ordem, $40,8 \%$ canais de segunda ordem e apenas $4,8 \%$ apresentam redes mais complexas, compostas por canais de terceira ordem. Quanto às grutas da área de estudo, os resultados foram muito similares, pois $57,4 \%$ têm canal de primeira ordem, $42,9 \%$ desenvolvem canais de segunda ordem e nenhuma das cavidades chega a desenvolver canais de terceira ordem (Figura 9).

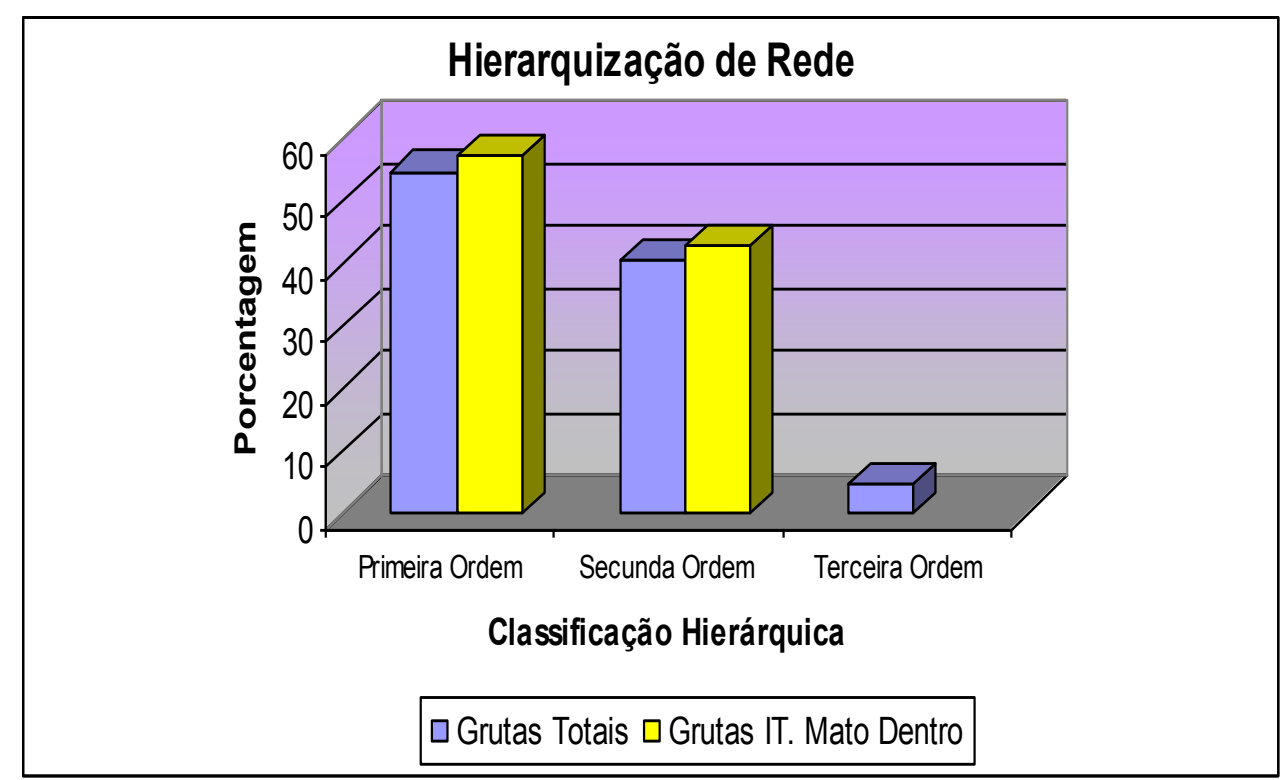

Figura 9 - Gráfico sobre classificação hierárquica em grutas siliciclásticas. (Fonte: FABRI, 2011).

\section{Sinuosidade}

De acordo com os resultados, observou-se que o grau de sinuosidade dos canais de drenagem das cavernas em rochas siliciclásticas não é muito grande. Cerca de $46,3 \%$ das grutas totais apresentam índices inferiores a 1,1, o que significa dizer que percorrem trechos não superiores do que $10 \%$ do caminho teoricamente mais curto. Mesmo os valores mais elevados são relativamente baixos, sendo 
que o maior índice registrado é pouco superior a 1,6 (Figura 10).

Os cursos que drenam as cavernas de Itambé do Mato Dentro também apresentam baixa sinuosidade, com índices muito próximo a

1. O maior valor encontrado é pouco superior a 1,1 , relativa à maior cavidade da área, a Gruta
Baixada das Crioulas I (Figura 11). Sendo assim, os canais tendem a ser retilíneos, em função do forte controle estrutural existente na maior parte das cavidades estudadas. A mesma relação foi observada para as cavernas de Ibitipoca por Silva (2004).

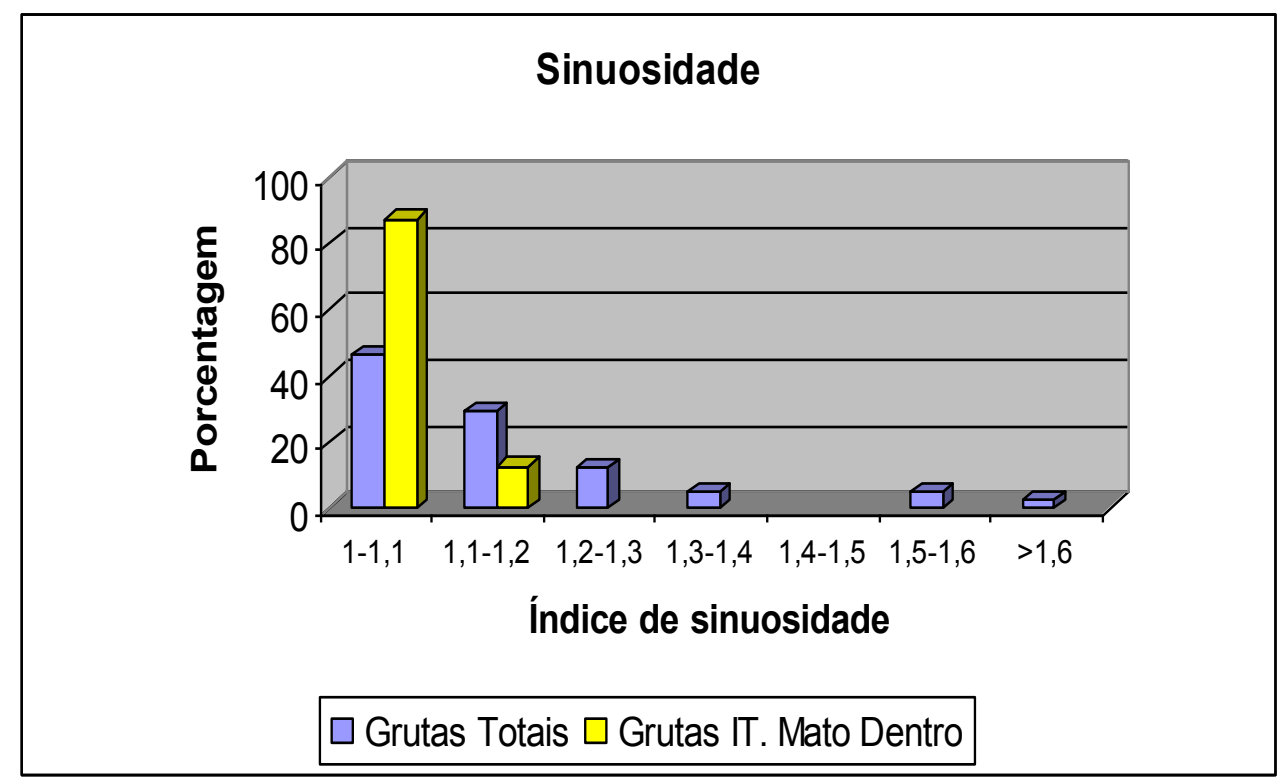

Figura 10 - Gráfico sobre sinuosidade para grutas siliciclásticas (Fonte: FABRI, 2011).

\section{RELAÇÕES ENTRE PARÂMETROS}

A seguir foram realizadas correlações entre alguns dos parâmetros analisados. Esse procedimento teve como propósito, obter um melhor entendimento sobre a inter-relação entre as diversas variáveis que influenciam na morfologia das cavernas siliciclásticas.

\section{Projeção Horizontal como variável independente}

O cruzamento da variável Projeção horizontal com os parâmetros área, distância entre extremos e conectividade apresentou uma correlação positiva moderada a forte, para ambos grupos de cavernas analisadas, conforme demonstra os valores de $r$ na Tabela 3 .

\begin{tabular}{|c|c|c|}
\hline \multirow{2}{*}{ Correlação } & \multicolumn{2}{|c|}{ Valor de $\mathbf{~}$} \\
\cline { 2 - 3 } & $\begin{array}{c}\text { Grutas } \\
\text { Itambé. } \\
\text { Mato Dentro }\end{array}$ & $\begin{array}{c}\text { Grutas } \\
\text { Totais }\end{array}$ \\
\hline PH x Área & 0,99 & 0,71 \\
\hline $\begin{array}{c}\text { PH X Distância entre } \\
\text { extremos }\end{array}$ & 0,98 & 0,85 \\
\hline PH x Conectividade & 0,89 & 0,84 \\
\hline PH x Densidade & $-0,32$ & $-0,3$ \\
\hline PH x No de entradas & 0,95 & 0,44 \\
\hline PH x Desnível & 0,92 & 0,57 \\
\hline PH x Sinuosidade & 0,94 & 0,26 \\
\hline
\end{tabular}

Tabela 3 - Valores de r para correlação entre Projeção Horizontal e outras variáveis 
Em relação ao parâmetro Área a correlação foi moderada para as grutas totais, já que o valor de $r$ foi de 0,71 (Tabela 2). Segundo Silva (2004), os pontos de maior dispersão das cavernas de Ibitipoca e a amostragem geral estão associados às cavernas maiores, pois estas tendem a desenvolver condutos mais estreitos e que provavelmente tem associação genética a coalescência de pequenos condutos, não sendo desenvolvidos segundo um plano, como é mais comum nas pequenas cavernas (Figura 11). Exemplo claro disso pode ser observado na Serra do Ibitipoca, onde a caverna com maior desenvolvimento, que é mais de quatro vezes superior à segunda, não apresenta a maior área, pois tem como características gerais condutos extensos, porém estreitos (SILVA, 2004).

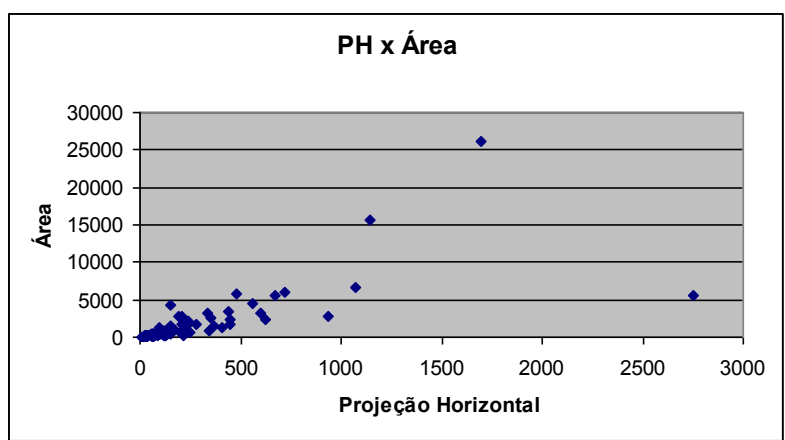

Figura 11 - Gráfico de dispersão entre os parâmetros Projeção Horizontal e Área para as Grutas Totais. Fonte: FABRI (2011).

Quanto às grutas de Itambé do Mato Dentro, o valor encontrado para $r$ foi de 0,99 , evidenciando uma correlação quase direta entre os dois parâmetros analisados (Tabela 3). Apesar da Gruta Baixada das Crioulas I ser considerada grande, esta não aparece no gráfico da Figura 13 como um ponto de dispersão, e sua área pode ser considerada, relativamente proporcional em relação a seu desenvolvimento.

A correlação como o parâmetro Distância entre extremos para as grutas totais, foi de 0,85 , indicando uma correlação positiva forte. Sobre as grutas da área de estudo, esta correlação foi quase perfeita (Tabela 3). Isso deve-se ao fato de que estas cavernas tendem a seguir um padrão retilíneo, em função do seu forte controle estrutural, salvo algumas exceções como a Gruta Baixada das Crioulas I que apresenta condutos sinuosos e padrão curvilíneo, bem como a Gruta dos Milagres I que desenvolveu um grande salão (FABRI, 2011).

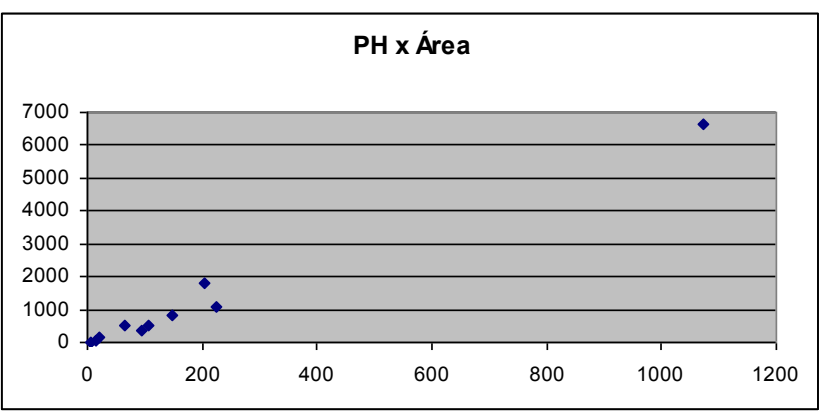

Figura 12 - Gráfico de dispersão entre os parâmetros Projeção Horizontal e Área para as Grutas de Itambé do Mato Dentro. Fonte: FABRI (2011).

Os parâmetros projeção horizontal e conectividade também apresentaram uma correlação forte (Tabela 2). Para as grutas totais essa relação torna-se mais estreita quanto menor a dimensão das grutas, conforme pode ser observado no gráfico da Figura 13. Quanto às grutas de Itambé do Mato Dentro, aquelas com até $200 \mathrm{~m}$ de projeção horizontal apresentam o predomínio de ausência de conectividade (Figura 14). 
A baixa conectividade das grutas em rochas siliciclásticas também está associada ao fato forte controle estrutural dessas feições, o que as tornam mais retilinizadas e pouco ramificadas (SILVA, 2004; FABRI, 2011).

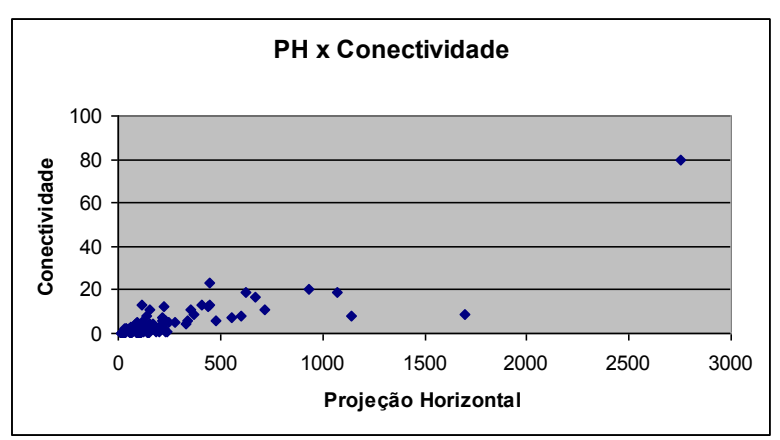

Figura 13 - Gráfico de dispersão entre os parâmetros projeção horizontal e conectividade para as Grutas totais. Fonte: FABRI (2011).

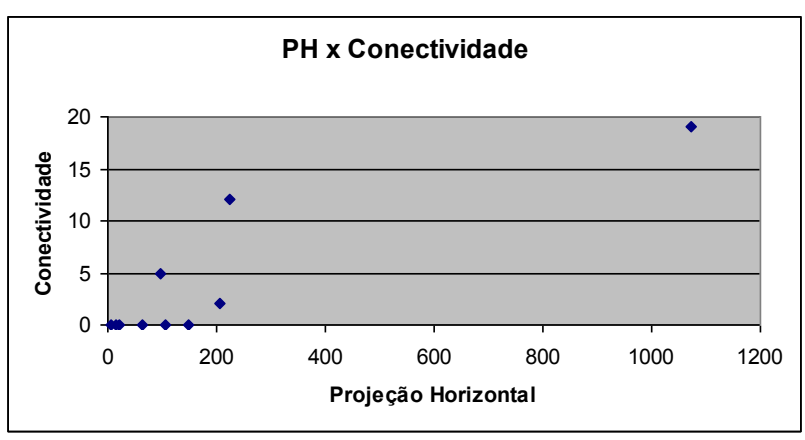

Figura 14 - Gráfico de dispersão entre os parâmetros projeção horizontal e conectividade para as Grutas de Itambé do Mato Dentro. Fonte: FABRI (2011).

O cruzamento da variável Projeção Horizontal com as demais variáveis não apresentou uma boa correlação para as grutas totais. Os valores de $r$ se mostraram baixos e, em alguns, casos negativos, portanto com correlação linear fraca (Tabela 3).

Contudo, o cruzamento dessas variáveis para as grutas de Itambé do Mato Dentro mostrou valores diferentes. De forma geral, a correlação entre essas variáveis foi positiva forte, com exceção da densidade, onde o é $r=$ 0,32 (Tabela 3).
Deste modo, a interpretação dos dados mostra que quanto maior o desenvolvimento da caverna, maior será o seu número de entradas, assim como o seu desnível. O mesmo foi observado para as análises das grutas de Ibitipoca por Silva (2004).

\section{Área como variável independente}

Os dados mostram que o parâmetro área como variável explicativa não obteve uma boa correlação, com exceção da projeção horizontal, como foi dito anteriormente, e a distância entre extremos (Tabela 3 ).

\begin{tabular}{|c|c|c|}
\hline \multirow{2}{*}{ Correlação } & \multicolumn{2}{|c|}{ Valor de r } \\
\cline { 2 - 3 } & $\begin{array}{c}\text { Grutas It. } \\
\text { Mato Dentro }\end{array}$ & $\begin{array}{c}\text { Grutas } \\
\text { Totais }\end{array}$ \\
\hline Área x PH & 0,99 & 0,71 \\
\hline $\begin{array}{c}\text { Área X Distância } \\
\text { entre extremos }\end{array}$ & 0,98 & 0,9 \\
\hline $\begin{array}{c}\text { Área x } \\
\text { Conectividade }\end{array}$ & 0,83 & 0,28 \\
\hline Área x Densidade & $-0,31$ & $-0,17$ \\
\hline $\begin{array}{c}\text { Área x No de } \\
\text { entradas }\end{array}$ & 0,94 & 0,23 \\
\hline Área x Desnível & 0,9 & 0,37 \\
\hline Área x Sinuosidade & 0,8 & 0,15 \\
\hline \multicolumn{2}{|c|}{ Tabela 3 - Valores de r para correlação entre área e } \\
\multicolumn{2}{|c|}{ outras variáveis. }
\end{tabular}

Em relação às cavidades de Itambé do Mato Dentro, a variável área apresentou uma boa correlação com os demais parâmetros. A única correlação fraca encontrada para $\mathrm{O}$ parâmetro área como variável independente, foi a densidade. O valor de $r=-0,31$, indica uma correlação negativa fraca (Tabela 3). 


\section{Densidade como variável independente}

A correlação do parâmetro como variável independente com outras variáveis é sempre negativa, fraca e moderada fraca, tanto para as grutas totais como para as grutas de Itambé do Mato Dentro. Mesmo para a variável projeção horizontal, cuja relação se mostrou forte quando esta foi empregada como variável independente (Tabela 4).

\begin{tabular}{|c|c|c|}
\hline \multirow{2}{*}{ Correlação } & \multicolumn{2}{|c|}{ Valor de r } \\
\cline { 2 - 3 } & $\begin{array}{c}\text { Grutas It. } \\
\text { Mato Dentro }\end{array}$ & Grutas Totais \\
\hline $\begin{array}{c}\text { Densidade } \mathbf{x} \\
\text { PH }\end{array}$ & $-0,32$ & $-0,3$ \\
\hline $\begin{array}{c}\text { Densidade X } \\
\text { Área }\end{array}$ & $-0,31$ & $-0,17$ \\
\hline $\begin{array}{c}\text { Densidade } \mathbf{x} \\
\text { Conectividade }\end{array}$ & $-0,35$ & $-0,28$ \\
\hline $\begin{array}{c}\text { Densidade } \mathbf{x} \\
\text { Dist. Extremos }\end{array}$ & $-0,38$ & $-0,36$ \\
\hline $\begin{array}{c}\text { Densidade } \mathbf{x} \\
\text { No de entradas }\end{array}$ & $-0,34$ & $-0,35$ \\
\hline $\begin{array}{c}\text { Densidade } \mathbf{x} \\
\text { Desnível }\end{array}$ & $-0,39$ & $-0,24$ \\
\hline $\begin{array}{c}\text { Densidade } \mathbf{x} \\
\text { Sinuosidade }\end{array}$ & $-0,24$ & $-0,21$ \\
\hline
\end{tabular}

Tabela 4 - Valores de $r$ para correlação entre densidade e outras variáveis.

\section{Distância entre extremos como variável} independente

Para as Grutas totais, o parâmetro distância entre extremos como variável explicável mostrou correlação moderada a fraca em relação às demais variáveis, exceto quando relacionada com as variáveis projeção horizontal e área, cuja correlação se mostra forte (Tabela 5).

Quanto às Grutas de Itambé do Mato Dentro, essa mesma análise apresentou uma correlação forte, exceto quando relacionada com a variável densidade, que apresentou uma correlação fraca negativa (Tabela 5).

A correlação entre distância entre extremos e conectividade apresentou um índice forte. Isto indica que, diferentemente das cavidades em geral, quanto maior a distância entre as extremidades, maior será o número de conexões. O mesmo pôde ser observado para as grutas estudadas na Serra do Ibitipoca (SILVA, 2004).

\begin{tabular}{|c|c|c|}
\hline \multirow{2}{*}{ Correlação } & \multicolumn{2}{|c|}{ Valor de r } \\
\cline { 2 - 3 } & $\begin{array}{c}\text { Grutas It. } \\
\text { Mato } \\
\text { Dentro }\end{array}$ & $\begin{array}{c}\text { Grutas } \\
\text { Totais }\end{array}$ \\
\hline Dist. Extremos x PH & 0,99 & 0,84 \\
\hline Dist. Extremos X Área & 0,99 & 0,9 \\
\hline $\begin{array}{c}\text { Dist. Extremos x } \\
\text { Conectividade }\end{array}$ & 0,83 & 0,5 \\
\hline $\begin{array}{c}\text { Dist. Extremos x } \\
\text { Densidade }\end{array}$ & $-0,38$ & $-0,35$ \\
\hline $\begin{array}{c}\text { Dist. Extremos x N } \\
\text { de entradas }\end{array}$ & 0,93 & 0,39 \\
\hline $\begin{array}{c}\text { Dist. Extremos x } \\
\text { Desnível }\end{array}$ & 0,93 & 0,58 \\
\hline $\begin{array}{c}\text { Dist. Extremos x } \\
\text { Sinuosidade }\end{array}$ & 0,93 & 0,21 \\
\hline
\end{tabular}

Tabela 5 - Valores de r para correlação entre distância entre extremos e outras variáveis.

De acordo com a Tabela 5, também se verifica um índice forte de 0,93 , para correlação entre distância entre extremos e número de entradas. Este valor é ainda mais elevado em relação àquele apresentado para as grutas de Ibitipoca, onde $r$ é 0,72 (SILVA, 2004). Isto sugere que quanto maior for distância entre extremos maior será o número de entradas. 


\section{Número de entradas}

Ao empregar o parâmetro número de entradas como variável explicável para as grutas totais, constatou-se que todas as correlações com as demais variáveis foram moderadas a fraca (Tabela 6). Isto demonstra que o parâmetro número de entradas é uma variável independente das demais, com pouca ou mesmo com ausência de relação com os outros parâmetros.

\begin{tabular}{|c|c|c|}
\hline \multirow[b]{2}{*}{ Correlação } & \multicolumn{2}{|c|}{ Valor de $\mathbf{r}$} \\
\hline & $\begin{array}{c}\text { Grutas } \\
\text { It. Mato } \\
\text { Dentro }\end{array}$ & Grutas Totais \\
\hline $\mathbf{N}^{0}$ Entradas $x$ PH & 0,95 & 0,44 \\
\hline $\begin{array}{c}\mathbf{N}^{0} \text { Entradas X } \\
\text { Área } \\
\end{array}$ & 0,94 & 0,23 \\
\hline $\begin{array}{l}\mathbf{N}^{0} \text { Entradas } x \\
\text { Conectividade }\end{array}$ & 0,9 & 0,51 \\
\hline $\begin{array}{c}\mathrm{N}^{0} \text { Entradas } \mathrm{x} \\
\text { Densidade }\end{array}$ & $-0,31$ & $-0,33$ \\
\hline $\begin{array}{l}N^{0} \text { Entradas } x \\
\text { Dist. Extremos }\end{array}$ & 0,93 & 0,39 \\
\hline $\begin{array}{c}\mathbf{N}^{0} \text { Entradas } \mathrm{x} \\
\text { Desnível }\end{array}$ & 0,91 & 0,32 \\
\hline
\end{tabular}

Tabela 6 - Valores de $r$ para correlação entre $n^{\circ}$ de entradas e outras variáveis.

Quanto às grutas de Itambé do Mato Dentro, os resultados se diferem bastante em relação as grutas em geral. Os índices de correlação do parâmetro número de entradas com as demais variáveis quase sempre são fortes. Todavia se aproxima dos valores encontrados para as grutas de Ibitipoca, cujos índices para essa correlação também foram bastante significativos (SILVA, 2004).

\section{CONSIDERAÇÕES FINAIS}

Como base nos resultados dos parâmetros morfométricos, foi possível concluir que, de forma geral, há uma tendência para ocorrência de valores baixos para as cavernas em rochas siliciclásticas. Isto demonstra que o processo de carstificação nessas rochas não é tão expressivo quanto nos terrenos carbonáticos, embora existam alguns valores de índices altos que se destoam dos demais.

A forte correlação registrada entre os parâmetros projeção horizontal, área e distância entre extremos, tanto para as grutas totais como para as cavernas estudadas, demonstra que existe um forte controle estrutural sobre as cavernas em rochas siliciclásticas. O parâmetro sinuosidade corrobora essa hipótese, por ter apresentado valores sempre baixos, mesmo para a Gruta Baixada das Crioulas I que possui grande porte e condutos mais sinuosos.

A correlação entre os demais parâmetros, contudo, em muitas situações não houve uma concordância entre os resultados obtidos para as grutas totais e as grutas estudadas. Em alguns casos, esta concordância foi maior em relação às grutas da Serra do Ibitipoca.

Tal situação deve-se provavelmente por dois motivos. O primeiro diz respeito ao número reduzido de amostras para as grutas de Itambé do Mato Dentro em relação às grutas totais, que apresenta uma a população muito maior. Outro fator está associado ao contexto geológico e geomorfológico no qual as cavernas se inserem. Para as grutas da área de estudo, presume-se que 
os processos e as respostas à carstificação guardem maiores semelhanças entre si, em relação as demais cavidades desenvolvidas sob diferentes cenários. No grupo das grutas totais estão incluídas cavidades desenvolvidas em arenitos e quartzitos de diferentes formações e que, portanto, apresentam histórias geológicas ou até mesmo, morfoclimáticas distintas.

Neste contexto, é possível que existam condições ambientais semelhantes entre a área estudada e a Serra do Ibitipoca, que propiciam respostas parecidas aos processos de carstificação para as cavernas de ambas as áreas, uma vez que as correlações registradas entre os parâmetros foram muito mais próximas entre estes dois grupos.

\section{AGRADECIMENTOS}

À Fundação de Amparo à Pesquisa do Estado de Minas Gerais (FAPEMIF), pelo apoio financeiro (CRA APQ 01652-09) e ao Instituto do Carste-MG pelo apoio logístico para a realização desta pesquisa.

\section{REFERÊNCIAS}

AULER, A.S. Quartzites caves of South America. Encyclopedia of Caves and Karst Science (Gunn, J. ed.) Fitzroy Dearborn, London, p. 611-613, 2004.

BRICHTA, A.; PATERNOSTER, K.; SCHOLL, W.U., TURINSKY, F. Die Gruta do Salitre bei Diamantina, Minas Gerais, Brasilien, Kein "Einsturzloch". Zeitschrift fur Geomorphologie, v. 24, p. 236-242, 1980.

Cruz, L. V., Pereira Filho, M., Lopes, M. V. C. O.; Mourão, R. C. 1999. In: Anais do XXV
Congresso Brasileiro de Espeleologia. Avaliação Espeleológica da Serra Cabeça de Boi, Fazenda Ponte-Itambé do Mato DentroMG. p. 27.

DOERR, S.H. Karst-like landforms and hydrology in quartzites of the Venezuelan Guyana Shield: Pseudokarst or "real" Karst? Zeitschrift fur Geomorphologie, v. 43, p.117,1999 .

FABRI, F.P. Estudo das cavernas quartzíticas da região de Itambé do Mato Dentro. 2011. 179 f Dissertação (Mestrado em Geografia) Instituto de Geociências, Universidade Federal de Minas Gerais, Belo Horizonte, 2011.

JENNINGS, J.N. Sanstone pseudokarst or karst? In: YOUNG, R. W.; NANSON, G.C. Aspects of Australian Sandstone Landscapes Australian and New Zealand Geomorphology Group Special Publication. v. 1, p. 21-30, 1983.

URBANI, F. Una revision preliminar sobre el desarrollo de cavidades $y$ otras formas relacionadas en las rocas cuarciferas del Grupo Roraima, Guayana Venezolana. Parte 2. Algunos comentarios sobre terminologia. Boletin de Geociencias, v. 7. p.10-14, 1986.

WHITE, W.B., JEFFERSON, G.L., HAMAN, J.F. Quartzite Karst in southeastern Venezuela. International Journal of Speleology, v. 2.p. 309-314, 1966.

WIEGAND J., FEY M., HAUS N., KARMANN I. Investigações Geoquímicas e hidroquímicas da gênese de carste em arenitos e quartzitos da Chapada Diamantina e Quadrilátero Ferrífero (Brasil). Z.dt. geol. Ges. V.155, p.61-90; 2004.

WRAY, R.A.L. Quartzite dissolution: Karst or pseudokarst? Cave and karst Science, v. 24, p.81-86, 1997.

SILVA, S.M. Carstificação em Rochas Siliciclásticas: Estudo de caso na Serra do Ibitipoca, Minas Gerais. MG. Belo Horizonte, 2004. 143 f. Dissertação (Mestrado em Geografia) - Universidade Federal de Minas Gerais, Belo Horizonte, 2004. 
SUGUIO, K. O relevo cárstico e a geoespeleologia. In: Geologia do Quaternário e mudanças ambientais: passado + presente $=$ Futuro? Paulo'a Comunicação e Artes Gráficas, p. 219-232, 1999.

SZCZERBAN, E., URBANI, F. Carsos de Venezuela. Parte 4: Formas carsicas en areniscas precambrianas del territorio federal Amazonas y estado Bolivar. Boletin de la Sociedade Venezolana de Espeleologia, v. 5, p.27-54, 1974.

YOUGER, P.L., STUNELL, J.M. Karst and pseudokarst: An artificial distinction? In: WILLEY J., SONS. Geomorphology and Groundwater (Brown, A.G.ed.), p. 121-142, 1995. 


\begin{tabular}{|c|c|c|}
\hline ISSN 0103-8427 & \multicolumn{2}{|c|}{ Caderno de Geografia, v.23, n.40, 2013} \\
\hline Parâmetro & Como foi medido & Finalidade \\
\hline $\begin{array}{l}\text { Projeção } \\
\text { Horizontal (PH) } \\
\quad \text { ou } \\
\begin{array}{l}\text { Desenvolvimento } \\
\text { linear (DL) }\end{array}\end{array}$ & $\begin{array}{l}\text { Para o cálculo da PH foi utilizado método de descontinuidade. O DL representa a } \\
\text { extensão medida pela somatória das galerias percorridas na gruta. Diferentemente da } \mathrm{PH} \text {, } \\
\text { as rampas inclinadas e os abismos entram diretamente na somatória. Para a análise desta } \\
\text { pesquisa foram utilizados um dos parâmetros, de acordo com as informações disponíveis. }\end{array}$ & $\begin{array}{l}\text { Medir a extensão da caverna sobre a planta da topografia ou } \\
\text { durante a topografia. }\end{array}$ \\
\hline $\begin{array}{l}\text { Distância entre } \\
\text { extremos }\end{array}$ & $\begin{array}{l}\text { Através do cálculo da distância máxima em linha reta entre os pontos extremos de uma } \\
\text { cavidade. }\end{array}$ & $\begin{array}{l}\text { Mostrar qual a distância em linha reta ocupada pelos condutos. } \\
\text { Esta distância pode ser limitada por algum fator inerente à } \\
\text { evolução da caverna como abatimentos ou entupimento de } \\
\text { condutos, mas também por fatores que limitam a exploração, } \\
\text { como condutos muito estreitos. }\end{array}$ \\
\hline Área & Valor obtido através do software AutoCad 2012. & Mostrar a área total ocupada pelos condutos de uma cavidade. \\
\hline Densidade & $\begin{array}{l}\text { Através da equação: } \\
\mathrm{Da}=\frac{\Delta \mathrm{c}}{\Delta \mathrm{p}} \text { sendo que } \Delta \mathrm{c}=\text { área da caverna e } \Delta \mathrm{p}=\text { área do polígono } \\
\text { Sendo sempre } \mathrm{Da} \leq 1\end{array}$ & $\begin{array}{l}\text { Utilizado para mostrar a ocupação relativa de uma caverna } \\
\text { projetada em uma figura geométrica retangular, na qual seja } \\
\text { possível inserir, na menor área possível, todos os condutos a } \\
\text { caverna. }\end{array}$ \\
\hline Desnível & Valor obtido a partir dos levantamentos topográficos de uma caverna. & $\begin{array}{l}\text { Utilizado para indicar a variação altimétrica entre o ponto mais } \\
\text { alto e o mais baixo de uma gruta. }\end{array}$ \\
\hline $\begin{array}{l}\text { Número de } \\
\text { entradas }\end{array}$ & Quantificando as aberturas para o meio externo. & Aponta locais para inputs e outputs de energia. \\
\hline Conectividade & Quantificando o número de conexões existentes entre os condutos em uma gruta. & $\begin{array}{l}\text { Aponta o grau de ramificação da cavidade, podendo guardar } \\
\text { relação com o padrão da mesma (reticulado ou não), existência } \\
\text { de tributários ativos ou fósseis, entre outros. Pode ser } \\
\text { fundamental também para indicar possíveis influências de } \\
\text { descontinuidades tectônicas ou estratigráficas. }\end{array}$ \\
\hline $\begin{array}{l}\text { Hierarquia da } \\
\text { Rede de } \\
\text { drenagem }\end{array}$ & $\begin{array}{l}\text { Conforme frequentemente empregado pela hidrologia clássica de superfícies, proposta por } \\
\text { Horton (1945) e modificado por Strahler (1952). }\end{array}$ & $\begin{array}{l}\text { Aponta a ordem hierárquica de canais presentes no interior da } \\
\text { caverna. }\end{array}$ \\
\hline Sinuosidade & $\begin{array}{l}\text { Considerou-se apenas o canal principal das cavidades que apresentam fluxo perene. A } \\
\text { sinuosidade é representada através da seguinte relação: } \\
\mathrm{S}=\underline{\gamma_{\mathrm{c}}} \\
\quad \mathrm{\gamma r}_{\mathrm{r}} \\
\text { sendo } \gamma_{\mathrm{c}}=\text { comprimento do canal e } \gamma \mathrm{r}=\text { comprimento do canal em linha reta. }\end{array}$ & $\begin{array}{l}\text { Representa a taxa relativa entre a distância percorrida pelo } \\
\text { fluxo em relação a uma linha reta. }\end{array}$ \\
\hline
\end{tabular}

Figura 1 - Parâmetros morfométricos utilizados para quantificar as caverna 